\title{
Workplace Bullying, Perceived Organizational Support and Turnover Intention in Manufacturing Factory: Evidence from China
}

\author{
Xiaohui Li \\ School of Business, Guangdong University of Foreign Studies, Guangzhou, China \\ Email:1id18@163.com
}

How to cite this paper: Li, X.H. (2020) Workplace Bullying, Perceived Organizational Support and Turnover Intention in Manufacturing Factory: Evidence from China. Open Access Library Journal, 7: e6886.

https://doi.org/10.4236/oalib.1106886

Received: October 9, 2020

Accepted: October 26, 2020

Published: October 29, 2020

Copyright () 2020 by author(s) and Open Access Library Inc.

This work is licensed under the Creative Commons Attribution International License (CC BY 4.0).

http://creativecommons.org/licenses/by/4.0/

\begin{abstract}
Basing on 305 samples from a manufacturing factory, this study examined the relationship among workplace bullying, perceived organizational support and turnover intention. The results show that: workplace bullying is excellent predictor of employees' turnover; perceived organizational support correlates negatively with the intention to leave the organization; and perceived organizational support plays a moderating role in the relationship between workplace bullying and turnover intention. These findings may have important implications from both the theoretical and the practical standpoints.
\end{abstract}

\section{Subject Areas \\ Human Resource Management}

\section{Keywords}

Workplace Bullying, Perceived Organizational Support, Turnover Intention

\section{Introduction}

Workplace bullying is broadly recognized to be a widespread and serious problem nowadays. Many countries, including China, have increasingly been focusing on raising awareness and preventing this particular problem in order to prevent its negative effects on the victim's health and work performance as well as on the organization itself.

The number of attacks and acts of violence workers directs at each other in the workplace is alarmingly high [1]. It has been estimated that about $15 \%$ of workers on a global basis are targets of systematic bullying behaviors, and $11 \%$ perceive themselves as victims of bullying [2]. The victim of such negative acts may 
choose to quit because of the adverse nature of the working conditions in which bullying occurs. Previous researches have provided evidence suggesting that exposure to workplace bullying is linked to employees intention or decision to leave [3]. Three reasons for quitting stand out among reasons given by the bullied: poor leadership, being exposed to negative behavior and health problems [4]. Moreover, the targets of bullying are not the only ones who suffer, previous research suggests that witnesses of bullying, co-workers, and even those accused of bullying, report similar consequences, such as increased stress, excessive absenteeism, reduced organizational commitment, low morale, and a decrease in job satisfaction. It is clear that this situation is alarming for the employees and the managers, but most of the current studies focus on physicians and nurses [1] [5] [6]. Bullying in manufacturing factory has not attracted enough attention. Compared with other workplaces, overall factory conditions are worse. In addition to the most visible issues, such as hours of work and accidents, the factory environment also consists of other issues which affect the labor force: elements such as hazardous substances, sanitary conditions, and welfare resources. Moreover, lacking of the early education, Chinese manufacturing workers are limited by their cultural quality and level of education, which in turn makes them harder to deal with the interpersonal relationship in their workplace. So, bullying is more likely to occur in factories and it is therefore crucial to conduct more research on it.

In this study, we will investigate the current situation of workplace bullying in manufacturing factories in China. First, we explore the effect of workplace bullying on workers' turnover intention. Second, we argue that perceived organizational support (POS) may reduce the negative consequences of workplace bullying and operate as a significant moderator in the relationship between the exposure to workplace bullying and turnover intention. As little research explores workplace bullying in Chinese manufacturing factory in general, or its relationships with POS, it is essential to establish that these relationships do indeed exist in the China context. An improved understanding of workplace bullying may improve the theoretical knowledge. In addition, it may provide useful elements to enhance the design of interventions aimed at combating the phenomenon. So, this thesis has its necessity and practical significance.

\section{Theory and Hypothesis}

\subsection{Workplace Bullying and Turnover Intention}

Workplace bullying is a problem prevalent in contemporary working life. According to Einarsen, Hoel (2003) [7], workplace bullying is defined as "harassing, offending, socially excluding someone or negatively affecting someone's work". To label something bullying it has to occur repeatedly, continuously and come from one or more persons, and the bullied have difficulties getting rid of this negative situation or defending himself/herself [8].

Employees' turnover intention is defined as a conscious and deliberate wil- 
lingness to leave the organization [9] and is potentially a sound predictor of actual turnover behaviors. Employees leave their jobs for a variety of reasons. One of the important reasons is work related stress [10].

Workplace bullying is a painful and aversive experience which has a negative impact on the bullied and even on the bystanders. Studies have shown bullying as a major stressor with detrimental consequences for psychology, emotion, health and well-being [11]. People exposed to long term and persistent workplace bullying have been reported to demonstrate anxiety, suspicious, depression, and suffer from headache, fatigue and sleep disturbance. What's more, individuals experiencing workplace bullying are more likely to impair their confidence [12], inhibit collegiality and cooperation [1], decrease their job satisfaction [13], increase employees' depression, make one or more serious work errors [14], as well as experiencing social isolation and stigmatization [15]. The majority of workplace bullying research indicates there is a positive relationship between workplace bullying and unfavorable outcomes for individuals and the organization. In addition, these studies agree that the consequences of workplace bullying often begin by impacting the psychological well-being of the target first, resulting in anxiety and depression, which then leads to a decrease in job satisfaction and increase in intention to leave. Steele, Rodgers (2020) [16] pointed that the correlations between bullying and psychological distress, job satisfaction, and affective commitment are all significant and for some outcomes greater than those involving the traditional job stressors.

When strain causes negative emotions and cognitions, one way to cope with this undesirable experience is emotional and physical withdrawal from the negative situation [17]. For the individual, withdrawing from the situation can represent an adaptive response to avoid the pain associated with bullying and a form of self-defense. For members of organizations, withdrawal can be manifested in thoughts and behaviors associated with planning to leave the organization. Thinking about leaving is reflected in turnover intentions [18]. We, therefore, propose the following hypothesis:

H1: Workplace bullying has a significant positive impact on employees' turnover intention.

\subsection{The Role of Perceived Organizational Support (POS)}

Organizational support is one of the most influential forms of management support that has conventionally been discussed in the literature on knowledge sharing in summary. Ling, Yang (2006) [19] show that Chinese employees' POS should be multi-dimension structures which are different from the single dimension of POS of Western countries. They divide organizational support into working support, identifying value and caring about well-being.

Social exchange theory suggests that in order for relationships to continue, both parties in the relationship must feel that they are receiving something of value [20]. In other words, if one party treats the other party well, the reciprocity norm compels the rewarded party to return the favor. According to the social 
exchange theory and the norm of reciprocity, POS makes the employees realize that they should pay back against the positive treatment they have received from their organization. What is often exchanged in an organizational context is dedication and loyalty. Employers, provide dedication and loyalty not only by offering a salary and benefits, but also by demonstrating that they value, respect, and care for the well-being of employees. Employees, in return, offer dedication and loyalty to the organization through reduced absenteeism and turnover along with heightened performance [20] [21]. We, therefore, propose the following hypothesis:

H2: POS has a significant negative impact on employees' turnover intention.

A social network and social support are valuable resources that not only enable individuals to cope with a wide variety of extant stressors but may also facilitate proactive coping efforts [22]. POS is the employee's belief that the organization values their contributions, cares about their well-being, and supports them in all the situations [23]. POS reduces psychological strain in stressful work situations, and has positive influence on the employee wellbeing and health. So, we argue that if the organization provided necessary support to the employee, the negative effect of workplace bullying could be mitigated. We, therefore, propose the following hypothesis:

H3: POS moderates the relationship between workplace bullying and turnover intention.

\section{Research Methods}

\subsection{Measures}

\subsubsection{Workplace Bullying}

The measure was designed by Chinese scholars Li, Nie (2011) [24] who believe that workplace bullying is a three-dimension construct (i.e. Personal attack, attack through work tasks and exclusion) in china. Cronbach' $\alpha=0.846$.

\subsubsection{Turnover Intention}

The measure was designed by Scott, Connaughton (1999) [25], including items such as "I would prefer another more ideal job than the one I now work in". Cronbach' $\alpha=0.822$.

\subsubsection{Perceived Organizational Support}

The organizational support scale developed by Chinese scholar Ling, Yang (2006) [19] was adopted. The scale includes three dimensions: working support, identifying value and caring about well-being. Cronbach' $\alpha=0.832$.

The above variables were measured using five-point Likert scale ranging from 1 (strongly disagree) - 5 (strongly agree). In addition, this study took age, gender, education and working life as control variables.

\subsection{Procedure and Sample}

Employees from a mid-sized manufacturing plant from Guangdong, China, were 
surveyed at a single point in time. This plant is one of the three manufacturing bases of $\mathrm{F}$ company which is dedicated at providing high quality and high performance and price ratio mobile terminal. Covering an area of $18,000 \mathrm{~m}^{2}$, this factory, which has nearly 1000 employees, is equipped with10 assembly, 5 packing lines and 100 sets of professional manufacturing and testing equipment which is able to fulfill monthly 1.2 to 1.5 million complete handset production. Employees were invited to participate in our study during the regular workday by their immediate supervisors. To reduce any perception of pressure to participate, supervisors were not present during data collection. Employees were told that their participation was voluntary and anonymous. Questionnaires were distributed by the researchers. Employees were told the research study was designed to measure employee attitudes and that their supervisors would not have access to completed questionnaires. Questionnaires were completed in approximately 20 minutes, and researchers waited to collect them back when completed. The total number of the questionnaires distributed was 350 , and the actual number of the collected questionnaires was 321. After disregarding 16 unqualified questionnaires, there were 305 questionnaires left and the effective response rate was $87.14 \%$. By the way, Part-time and temporary employees were excluded from this study because we felt their turnover intention may be related to the temporary or part-time nature of the job itself.

In the samples we collected, $2.8 \%$ were under 20 years of age, $80.1 \%$ were between 21 and 30 years of age, $9.1 \%$ were between 31 and 40 years of age, $8 \%$ were over 40 years old; males accounted for $62 \%$ and females accounted for $38 \%$; $82.3 \%$ of the participants were junior college or below, $14.1 \%$ were undergraduate and $3.6 \%$ were master's degree or above; $39 \%$ of the participants worked between six months and one year, $45.3 \%$ for more than one year and less than three years, and $15.7 \%$ for more than three years. Basic information of respondents is shown in Table 1.

\section{Results}

\subsection{The Actualities of Bullying in Factory}

Among the workers participating in this study, 65.9\% stated that they encountered bullying behaviors in the workplace once or for more times over the last three months. The most frequent bullying behaviors experienced by the workers were in the form of "Work-related bullying" (50.7\%), which included behaviors such as "Always having your performance evaluated negatively", "Considering the work you have done as without value and importance", and "Always having errors found in your work and work results". This sub-scale was followed by the "Personal attack" sub-scale 32.1\%, which included behaviors such as "Being verbally threatened". The participants reported that they experienced these behaviors from their managers, their liners and their colleagues. And "Social exclusion" was $21.5 \%$. These results show that workers' exposure to bullying in factories is high in China and should be given enough attention. 
Table 1. Basic information of respondents.

\begin{tabular}{ccc}
\hline Question & Option & Percentage (\%) \\
\hline Gender & Male & 62 \\
& Female & 38 \\
\hline Age & $\leq 20$ & 2.8 \\
& $21-30$ & 80.1 \\
& $31-40$ & 9.1 \\
& $\geq 41$ & 8 \\
\hline Education & junior college or below & 82.3 \\
& undergraduate & 14.1 \\
& master's degree or above & 3.6 \\
\hline Seniority & $<1$ year & 39 \\
& $1-3$ years & 45.3 \\
\hline & $>3$ years & 15.7 \\
\hline
\end{tabular}

\subsection{Common Method Deviation Test and Confirmatory Factor Analysis}

We promoted Harman's one-factor test and results showed that the first factor was below 50 percent threshold and explained 22.574 percent of variance, indicating low concerns of the common method bias problem.

As can be seen from Table 2, the hypothesized three-factor model demonstrates a more acceptable fit to the data than other models. Results show that these three variables have good discriminant validity.

\subsection{Descriptive Statistics}

Means, standard deviations and reliabilities of variables involved in this paper are presented in Table 3. As can be seen from Table 2, there is a significant positive correlation coefficient of $0.463(P<0.01)$ between workplace bullying and turnover intention, showing that the higher the sense of being bullied, the higher intentions to leave the organization. $\mathrm{H} 1$ is initially validated. There is a significant correlation coefficient of $-0.512(P<0.001)$ between POS and turnover intention, showing that the higher POS, the lower intention to leave the organization. $\mathrm{H} 3$ is initially validated. The results lay the foundation for the follow-up regression analysis.

\subsection{Regression Analysis and Hypothetical Test}

To test $\mathrm{H1}-\mathrm{H} 3$, we used the method proposed by Chinese scholars Wen, Hau (2005) [26]. IBM SPSS Statistics Version 22 was used to analyze the data obtained from the questionnaire and the results of the test are presented in Table 4. 
Table 2. Confirmatory factor analysis $(\mathrm{N}=305)$.

\begin{tabular}{cccccccc}
\hline Model & $\mathrm{X}^{2}$ & $\mathrm{df}$ & $\mathrm{X}^{2} / \mathrm{df}$ & $\mathrm{CFI}$ & $\mathrm{TLI}$ & RMSEA & SRMR \\
\hline 1) (1), (2), (3) & 66.706 & 26 & 2.566 & 0.963 & 0.954 & 0.067 & 0.0451 \\
2) (1) + (3), (2) & 128.762 & 35 & 3.679 & 0.931 & 0.885 & 0.128 & 0.0543 \\
3) (1) + (2), (3) & 109.399 & 35 & 3.126 & 0.937 & 0.918 & 0.105 & 0.0486 \\
4) (1) (2) + (3) & 134.654 & 35 & 3.847 & 0.908 & 0.864 & 0.112 & 0.0545 \\
5) (1) + (2) + (3) & 160.859 & 37 & 4.348 & 0.887 & 0.852 & 0.139 & 0.0693 \\
\hline
\end{tabular}

Note: (1) workplace bullying, (2) Perceived Organizational Support, (3) turnover intention, "+" is a combination of representatives as a factor.

Table 3. Describe statistics and related analysis.

\begin{tabular}{lccccc}
\hline & M & SD & 1 & 2 & 3 \\
\hline 1) Workplace Bullying & 2.87 & 0.63 & 1 & & \\
2) POS & 3.34 & 0.51 & $-0.212^{\star}$ & 1 & \\
3) Turnover intention & 3.61 & 1.14 & $0.463^{* *}$ & $-0.512^{* * *}$ & 1 \\
\hline
\end{tabular}

Notes: ${ }^{*} \mathrm{p}<0.05,{ }^{* *} \mathrm{p}<0.01,{ }^{* * *} \mathrm{p}<0.001$.

Table 4. Hierarchical regression analysis.

\begin{tabular}{ccccc}
\hline & \multicolumn{4}{c}{ Dependent: turnover intention } \\
\cline { 2 - 4 } & Mode 1 & Model 2 & Model 3 & Model 4 \\
\hline Gender & -0.045 & 0.086 & 0.101 & 0.169 \\
Age & $-0.584^{* *}$ & $-0.452^{*}$ & -0.310 & -0.337 \\
Education & -0.041 & -0.049 & -0.053 & -0.064 \\
Seniority & 0.010 & -0.034 & -0.044 & -0.059 \\
Workplace bullying (WB) & & $0.636^{* * *}$ & $0.603^{* * *}$ & $0.413^{* * *}$ \\
POS & & & $-0.545^{* * *}$ & $-0.512^{* * *}$ \\
WB $\times$ POS & & & $0.485^{* *}$ \\
$\mathrm{R}^{2}$ & 0.078 & 0.268 & 0.383 & 0.401 \\
$\mathrm{~F}$ & $3.875^{* *}$ & $15.368^{* * *}$ & $12.411^{* * *}$ & $11.662^{* * *}$ \\
$\Delta \mathrm{R}^{2}$ & 0.078 & 0.190 & 0.115 & 0.018 \\
\hline
\end{tabular}

Notes: ${ }^{*} \mathrm{p}<0.05,{ }^{* *} \mathrm{p}<0.01,{ }^{* * *} \mathrm{p}<0.001$.

In Model 2, workplace bullying is positively related to turnover intention $(\mathrm{b}=$ $0.636, \mathrm{p}<0.001)$ indicating that exposure to workplace bullying will increase the intention to leave the organization. Therefore, $\mathrm{H} 1$ is supported.

In Model 3, Perceived Organizational Support (POS) is negatively related to 
turnover intention $(\mathrm{b}=-0.545, \mathrm{p}<0.001)$, indicating that organizational support decreases the frequency of thoughts about leaving the organization. $\mathrm{H} 2$ is supported.

In Model 4, the cross-term of workplace bullying and POS is entered into the regression equation, and the coefficient is significant $(b=0.485, p<0.01)$, indicating that the relationship of workplace bullying and turnover intention is moderated by POS. H3 is supported.

Figure 1 illustrates the moderating effect of POS. As can be seen, the slope of low POS group is higher than that of high POS group, indicating that POS decreases the positive explanation of the relationship between workplace bullying and employee turnover intention. Employees with low POS are more likely to leave the organizations than employees with high POS are. H3 is further verified.

\section{Discussion and Conclusion}

\subsection{Theoretical Implications}

This study contributes to the limited research regarding workplace bullying in the Chinese context by quantifying the links between workplace bullying, POS and turnover intention.

Data show that workplace bullying has a significant positive impact on turnover intention. This confirms the results of several previous studies [27] [28]. Furthermore, turnover intention has been found to be a significant predictor of turnover behavior, which has substantial cost implications for the organization such as a low staff satisfaction, sickness absence, workers compensation and reduced productivity. In other words, Workplace bullying is a worldwide concern with devastating effects on both the targets and organizations.

Another objective of this study was to determine whether POS moderates the relationship between workplace bullying and turnover intention. The results confirmed this moderating effect. Perceived Organizational Support does diminish the adverse effect of workplace bullying on intention to leave.

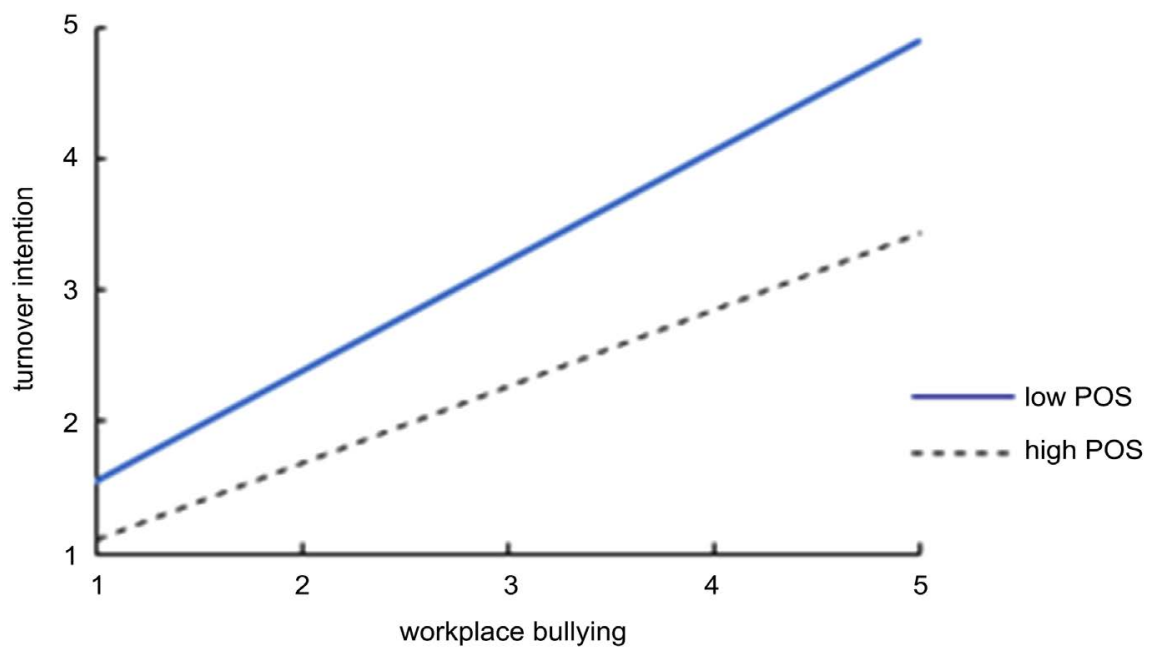

Figure 1. Moderating effect of POS. 


\subsection{Practical Implications}

Workplace bullying is broadly recognized to be a serious problem nowadays. Awareness needs to be raised about what constitutes bullying behavior and effective interventions are needed to stop workplace bullying. The results of this study suggest that a lack of POS will increase bullying victims' propensity to leave the organization. This intensifies the need for organizations to provide a supportive environment for their employees, especially those being targeted by bullies.

\subsection{Limitations and Extensions}

First, the survey sample size is not large enough, and concentrated on the Pearl River Delta region in China. Future research should adopt a wider perspective and include more data from different industries, different fields and different population. Second, the way to get the data too limited, basic from employee self-report questionnaire, and based on the analysis of firms' cross-sectional data, where the time lag has not been adequately addressed. Future research might consider including data from paired questionnaire, and collecting longitudinal data of samples rather than the cross-sectional data. Thirdly, although we examined personality characteristics of victims as potential correlates of workplace bullying, personality characteristics of both victims and perpetrators are likely to play a role in bullying. Future research should examine the relative influences of victims' and perpetrators' personality characteristics in predicting workplace bullying.

\section{Project}

The research is supported by Guangdong University of Foreign Studies (Grant No. 15Q27).

\section{Conflicts of Interest}

The author declares no conflicts of interest regarding the publication of this paper.

\section{References}

[1] Ekici, D. and Beder, A. (2014) The Effects of Workplace Bullying on Physicians and Nurses. Australian Journal of Advanced Nursing, 31, 24-33.

[2] Nielsen, M.B., Matthiesen, S.B. and Einarsen, S. (2010) The Impact of Methodological Moderators on Prevalence Rates of Workplace Bullying. A Meta-Analysis. Journal of Occupational and Organizational Psychology, 83, 955-979. https://doi.org/10.1348/096317909X481256

[3] Coetzee, M. and Van Dyk, J. (2017) Workplace Bullying and Turnover Intention: Exploring Work Engagement as a Potential Mediator. Psychological Reports, 121, 375-392. https://doi.org/10.1177/0033294117725073

[4] Hogh, A., Hoel, H. and Carneiro, I.G. (2011) Bullying and Employee Turnover among Healthcare Workers: A Three-Wave Prospective Study. Journal of Nursing 
Management, 19, 742-751. https://doi.org/10.1111/j.1365-2834.2011.01264.x

[5] Serpil, Ç.D., İbrahim, T. and Aytolan, Y. (2018) Mobbing Behaviors Encountered by Nurses and Their Effects on Nurses. International Journal of Caring Sciences, 11, 905-913.

[6] Yildirim, D. (2010) Bullying among Nurses and Its Effects. International Nursing Review, 56, 504-511. https://doi.org/10.1111/j.1466-7657.2009.00745.x

[7] Einarsen, S., et al. (2003) The Concept of Bullying at Work: The European Tradition. Isla De Arriarán Revista Cultural Y Científica, 63, 175-212.

[8] Einarsen, S.L. and Skogstad, A. (1996) Bullying at Work: Epidemiological Findings in Public and Private Organizations. European Journal of Work \& Organizational Psychology, 5, 185-201. https://doi.org/10.1080/13594329608414854

[9] Tett, R.P. and Meyer, J.P. (1993) Job Satisfaction, Organizational Commitment, Turnover Intention, and Turnover: Path Analyses Based on Meta-Analytic Findings. Personnel Psychology, 46, 259-293. https://doi.org/10.1111/j.1744-6570.1993.tb00874.x

[10] Elçi, M., et al. (2012) The Impact of Ethical Leadership and Leadership Effectiveness on Employees' Turnover Intention: The Mediating Role of Work Related Stress. Procedia-Social and Behavioral Sciences, 58, 289-297. https://doi.org/10.1016/j.sbspro.2012.09.1003

[11] Sultana, A., Sarker, M.N.I. and Prodhan, A.S. (2017) Job Satisfaction of Public and Private Primary School Teachers of Bogra District in Bangladesh. Journal of Sociology and Anthropology, 1, 41-46.

[12] Leisy, H.B. and Ahmad, M.J.B.M.E. (2016) Altering Workplace Attitudes for Resident Education (A.W.A.R.E.): Discovering Solutions for Medical Resident Bullying through Literature Review. BMC Medical Education, 16, 127.

https://doi.org/10.1186/s12909-016-0639-8

[13] Jiang, J., Jiao, D. and Rong, W. (2012) Workplace Bullying, Employees' Depression and Job Satisfaction: Moderating Effect of Coping Strategies. Chinese Mental Health Journal, 26, 610-615.

[14] Paice, E. and Smith, D. (2009) Bullying of Trainee Doctors Is a Patient Safety Issue. The Clinical Teacher, 6, 13-17. https://doi.org/10.1111/j.1743-498X.2008.00251.x

[15] Johnson, S.L. (2010) International Perspectives on Workplace Bullying among Nurses: A Review. International Nursing Review, 56, 34-40. https://doi.org/10.1111/j.1466-7657.2008.00679.x

[16] Steele, N.M., Rodgers, B. and Fogarty, G.J. (2020) The Relationships of Experiencing Workplace Bullying with Mental Health, Affective Commitment, and Job Satisfaction: Application of the Job Demands Control Model. International Journal of Environmental Research and Public Health, 17, 2151. https://doi.org/10.3390/ijerph17062151

[17] Nathan, P.P., Jeffery, A.L. and Marcie, A.L. (2007) Differential Challenge Stressor-Hindrance Stressor Relationships with Job Attitudes, Turnover Intentions, Turnover, and Withdrawal Behavior: A Meta-Analysis. The Journal of Applied Psychology, 92, 438-454. https://doi.org/10.1037/0021-9010.92.2.438

[18] Lance, et al. (2008) The Development and Validation of the Workplace Ostracism Scale. Journal of Applied Psychology, 93, 1348-1366.

[19] Ling, W.Q., Yang, H.J. and Fang, L.L. (2006) Perceived Organizational Support (POS) of the Employees. Acta Psychologica Sinica, 38, 281-287.

[20] Dawley, D., Houghton, J.D. and Bucklew, N.S. (2010) Perceived Organizational 
Support and Turnover Intention: The Mediating Effects of Personal Sacrifice and Job Fit. Journal of Social Psychology, 150, 238-257. https://doi.org/10.1080/00224540903365463

[21] Srivastava, S. and Agrawal, S. (2020) Resistance to Change and Turnover Intention: A Moderated Mediation Model of Burnout and Perceived Organizational Support. Journal of Organizational Change Management. https://doi.org/10.1108/JOCM-02-2020-0063

[22] Aspinwall, L.G. and Taylor, S.E. (1997) A Stitch in Time: Self-Regulation and Proactive Coping. Psychological Bulletin, 121, 417-436. https://doi.org/10.1037/0033-2909.121.3.417

[23] Rhoades, L. and Eisenberger, R. (2002) Perceived Organizational Support: A Review of the Literature. The Journal of Applied Psychology, 87, 698-714. https://doi.org/10.1037/0021-9010.87.4.698

[24] Li, Y., et al. (2011) The Structure and Measurement of Workplace Bullying in China. Psychological Science, 34, 1201-1208.

[25] Scott, C.R., et al. (1999) The Impacts of Communication and Multiple Identifications on Intent to Leave: A Multimethodological Exploration. Management Communication Quarterly, 12, 400-435. https://doi.org/10.1177/0893318999123002

[26] Wen, Z.L., Hau, K.-T. and Chang, L. (2005) A Comparison of Moderator and Mediator and Their Applications. Acta Psychologica Sinica, 37, 268-274.

[27] Berthelsen, M., et al. (2011) Do They Stay or Do They Go? International Journal of Manpower, 32, 178-193. https://doi.org/10.1108/01437721111130198

[28] Schalkwyk, L.-M.V., Els, C. and Rothmann, I. (2011) The Moderating Role of Perceived Organisational Support in the Relationship between Workplace Bullying and Turnover Intention across Sectors in South Africa. Journal of Human Resource Management, 9, a384. https://doi.org/10.4102/sajhrm.v9i1.384 